(Deshpande et al 1976; Jayakumar et al 1987). An association with other diseases causing skeletal hyperostosis is now recognised, including diffuse idiopathic skeletal hyperostosis (DISH). Resnick et al (1978) observed OPLL in $50 \%$ of cases of DISH, and Tsuyama (1984) in $24 \%$. Fluorosis causes extensive narrowing of the spinal canal and the root exit foramina; OPLL may cause further spinal stenosis. Probably because fluorosis produces more diffuse changes, our results of surgery in patients with fluorosis have been disappointing.

Although none of the authors have received or will receive benefits for personal or professional use from a commercial party related directly or indirectly to the subject of this article, benefits have been or will be received but are directed solely to a research fund, foundation, educational institution, or other non-profit institution with which one or more of the authors is associated.

\section{REFERENCES}

Deshpande RP, Dinakar I, Reddy MS. Calcified posterior longitudinal ligament and myelopathy. Indian J of Orthopaedics 1976; 10:78-82.

Jayakumar PN, Sastry Kolluri VR, Jain VK, Chandramouli SA, Das BS. Ossified posterior longitudinal ligament. Neurology India 1987; $35: 55$

Jolly SS. Endemic fluorosis. In: Ahuja MMS, ed. Progress in clinical medicine in India. Second edition. India, etc: Arnold-Heinemann, $1981: 106-25$.

Reddy DR, Reddy DS. Management of fluorotic spinal compression. Neurology India 1987; 35:369-74.

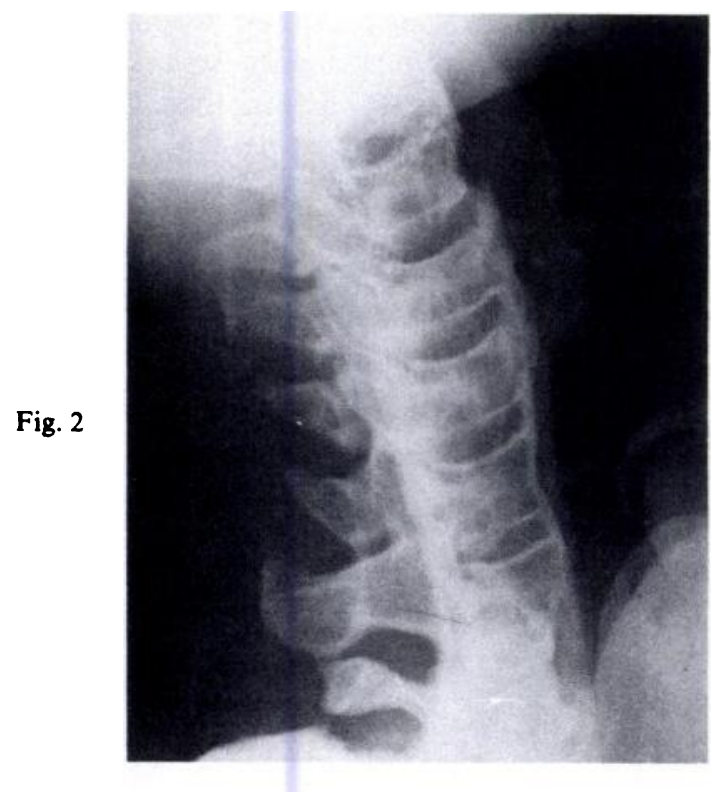

Resnick D, Guerra J, Robinson CA, Vint VC. Association of diffuse idiopathic skeletal hyperostosis (DISH) and calcification and ossification of the posterior longitudinal ligament. $A J R$ 1978; $131: 1049-53$.

Tsuyama N. Ossification of the posterior longitudinal ligament of the spine. Clin Orthop 1984; 184:71-84.

\title{
SUPRASCAPULAR NERVE ENTRAPMENT IN AN ARTHRODESED SHOULDER
}

\section{LENNART SJÖSTRÖM, BENGT MJÖBERG}

Suprascapular nerve entrapment is rarely considered as a cause of shoulder pain. We report relief of pain in an arthrodesed shoulder by decompression of the nerve.

Case report. An epileptic man in his 20 s developed painful post-traumatic arthritis after delayed diagnosis of a posterior dislocation of his left shoulder. Four years later he had a successful arthrodesis and his pain was relieved.

One year after the operation he complained of aching pain in the scapular region radiating down the lateral side of the arm to the elbow. The pain was constant but aggravated by use of the arm and the patient had been unemployed for two years. Repeated radiographs confirmed that the arthrodesis was sound.

The diagnosis of entrapment of the suprascapular nerve was considered, because tenderness was maximal over the suprascapular notch. Injections of local anaesthetic and steroid gave prompt pain relief for one to two

L. Sjöström, MD, Orthopaedic Surgeon

B. Mjöberg, MD, PhD, Associate Professor

Department of Orthopaedics, Uppsala University Hospital, S-751 85

Uppsala, Sweden.

Correspondence to Dr L. Sjöström.

(C) 1992 British Editorial Society of Bone and Joint Surgery $0301-620 X / 92 / 3 R 43 \$ 2.00$

J Bone Joint Surg [ Br] 1992; 74-B : 470-1. weeks. Electromyography showed denervation potentials in the supraspinatus but not in the infraspinatus.

At operation, through an incision just above the spine of the scapula, the transverse ligament was excised and the notch widened with a rongeur (Rask 1977). The nerve appeared normal. The pain was immediately and completely relieved: three weeks later the patient returned to heavy manual work in a timber yard and was still painfree after one year.

Discussion. The most common cause of suprascapular nerve entrapment in the suprascapular notch is direct trauma to the shoulder (Kopell and Thompson 1976; Laulund et al 1984; Hadley, Sonntag and Pittman 1986). The nerve has no cutaneous afferent fibres and the pain is therefore a deep, dull ache which may be made worse by shoulder movements, particularly adduction of the extended arm across the body. There is often wasting of the spinati muscles and local tenderness over the notch. The diagnosis may be confirmed by a suprascapular nerve block and by electromyography. Repeated nerve blocks with or without steroids may be curative but operative decompression usually gives permanent relief (Laulund et al 1984; Hadley et al 1986).

Another rare cause is frozen shoulder, which necessitates increased scapulothoracic movement which can produce a neuropathy in individuals with a narrow suprascapular notch (Kopell and Thompson 1976). 
Most shoulders are arthrodesed in $20^{\circ}$ to $50^{\circ}$ of abduction, so that the suprascapular nerve is stretched when the arm is hanging by the side and may be more vulnerable to acute or chronic trauma. The arthrodesed shoulder is not always pain free even if there is radiographic evidence of bone fusion; Cofield and Briggs (1979) reported moderate or severe pain in 17 of 66 arthrodesed shoulders, and Vastamäki (1987) in eight of 23. Entrapment of the suprascapular nerve should be considered as the cause of pain in these cases.

No benefits in any form have been received or will be received from a commercial party related directly or indirectly to the subject of this article.

\section{REFERENCES}

Cofield RH, Briggs BT. Glenohumeral arthrodesis: operative and longterm functional results. J Bone Joint Surg [Am] 1979; 61-A : 668-77.

Hadley MN, Sonntag VKH, Pittman WH. Suprascapular nerve entrapment: a summary of seven cases. $J$ Neurosurg 1986; 64: 843-8.

Kopell HP, Thompson WAL. Suprascapular nerve. In: Peripheral entrapment neuropathies. Huntington, New York: Robert E. Krieger Publishing Company, 1976:147-59.

Laulund T, Fedders O, Segaard I, Kornum M. Suprascapular nerve compression syndrome. Surg Neurol 1984; 22:308-12.

Rask MR. Suprascapular nerve entrapment: a report of two cases treated with suprascapular notch resection. Clin Orthop 1977; 123:73-5.

Vastamäki M. Shoulder arthrodesis for paralysis and arthrosis. Acta Orthop Scand 1987; 58:549-53.

\title{
ULTRASOUND DIAGNOSIS OF NEONATAL FRACTURE SEPARATION OF THE UPPER HUMERAL EPIPHYSIS
}

\author{
C. B. HOWARD, E. SHINWELL, M. NYSKA, I. MELLER
}

Injury to the upper limb during a difficult birth may produce swelling, reluctance to move the arm and discomfort on passive movement. Possible causes include brachial plexus injury, shoulder dislocation, fracture of the clavicle, fracture separation of the upper humeral epiphysis, fracture of the humeral shaft, septic arthritis and even osteomyelitis. Plain radiographs may show a fracture, but are of limited value in diagnosing separation of the unossified epiphysis of the neonatal head of the humerus. We present a case in which ultrasound showed a Salter type-1 injury (Salter and Harris 1963) despite a normal radiograph.

Case report. A 33-week mature girl was delivered by
Caesarean section, at which considerable difficulty was encountered during delivery of the shoulders, upper limbs and trunk. Her birth-weight was only $1870 \mathrm{~g}$ and she was seen not to move her left arm. The upper part of the arm became swollen, and movement caused her to cry.

Plain radiographs were normal, but examination using a Sonoline SL 1 with a $7.5 \mathrm{MHz}$ linear transducer showed some periosteal elevation at the junction of the cartilaginous humeral head and the metaphysis. Abduction of the arm demonstrated movement between the humeral head and the metaphysis. In Figure 1 both humeri are shown. On the left, the fractured humerus is abducted, the shaft is in a valgus position, with elevation

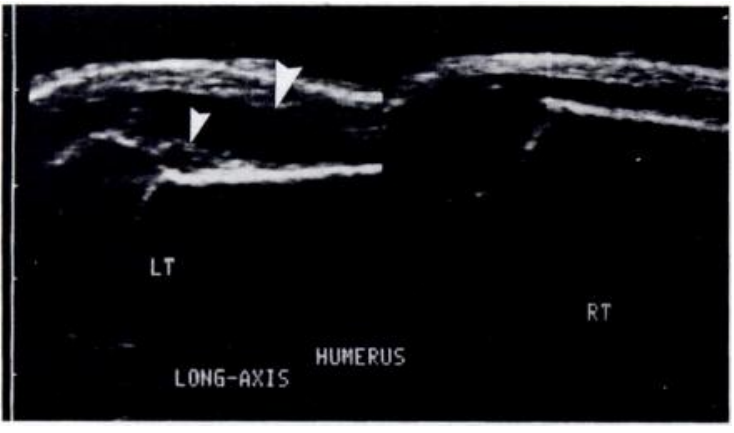

Fig. 1

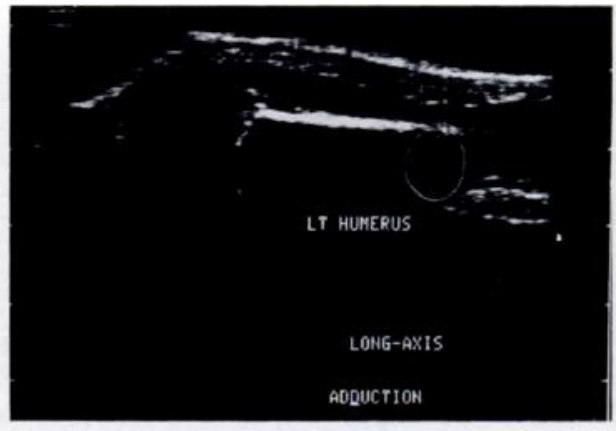

Fig. 2

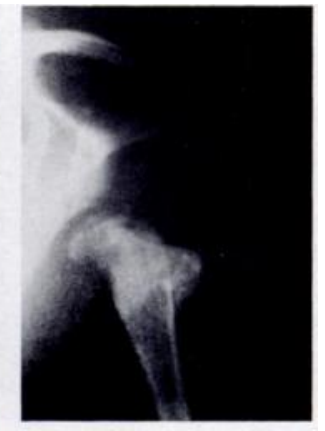

Fig. 3
C. B. Howard, FRCS, Orthopaedic Consultant

E. Shinwell, LRCP, MRCS, Consultant in Neonatal Medicine M. Nyska, MD, Orthopaedic Consultant

I. Meller, MD, Orthopaedic Consultant

Department of Orthopaedic and Traumatic Surgery, Soroka Medical Centre, Ben Gurion University of the Negev, Beer-Sheva, Israel.

Correspondence to $\mathrm{Mr} \mathrm{C}$. B. Howard.

(C) 1992 British Editorial Society of Bone and Joint Surgery 0301-620X/92/3R49 \$2.00

J Bone Joint Surg [ Br] 1992; 74-B : 471-2. of the upper part of the periosteum (small arrow), and the deltoid (large arrow) is displaced laterally. The unaffected right arm is shown for comparison. In Figure 2 the left arm is imaged in adduction and the shaft is now seen to be reduced. Treatment by immobilisation underneath clothing relieved all symptoms within three days. Plain radiographs at three weeks confirmed the diagnosis (Fig. 3). 